\title{
Genetic Variability, Heritability and Genetic Advance for Some Yield and Yield Related Traits Among 36 Ethiopian White Lupine (Lupinus albus L.) Genotypes
}

\author{
Temesgen Bedassa Gudeta \\ Department of Biology, Madda Walabu University, P.O. Box: 247, Bale-Robe, Ethiopia
}

\begin{abstract}
The present study was conducted on 36 white lupin (Lupinus albus L.) genotypes to estimate the genetic variability, broad sense heritability and genetic advance. The genotypes were grown in Randomized Complete Block Design with three replications at Research Site of Madda Walabu University and Gasera farmers' farm land in southeastern part of Ethiopia in 2017. Data were collected on 18morpho-agronomic quantitative characters. The collected data were adjusted to mean values and the mean values were standardized to mean of zero and unity variance in order to minimize biases due to differences in scales of measurement and then subjected to analysis of variance using SAS 9.2software. The combined analysis of variance showed very highly significant $(\mathrm{p} \leq 0.0001)$ and highly significant $(\mathrm{p} \leq 0.01)$ differences among the studied genotypes for all characters, except for the traits number of primary branches (NPB) and pod thickness (PT) at both experimental sites. This indicated the existence of variability and hence the potential for selection and improvement for those characters other than NPB and PT. Wide range of variability was observed among the genotypes. The maximum performance value $(9711.0 \mathrm{Kg}$ ha1) for the trait seed yield per hectare was observed on the genotype AC.26637; whereas the minimum $(787.6 \mathrm{Kg}$ ha-1) was exhibited by the accession AC.239051. The phenotypic coefficient of variation (PCV) was greater than that of genotypic coefficient of variation $(\mathrm{GCV})$ for all the traits indicating the influence of environmental variation to the total variation. Higher values of $\mathrm{h}^{2} \%$ were observed for the traits such as days to flowering $(98 \%)$, pod length $(97 \%)$ and seed yield per plot (SYP) (97\%). Some traits, such as hundred seed weight and SYP showed high values of genetic advance as percent of mean. Hence, these traits can be used to improve white lupin through application of selection and other breeding methods.
\end{abstract}

Keywords: Accession, GC V, genetic advance, heritability, PC V, White lupin, Yield related traits.

DOI: $10.7176 / \mathrm{FSQM} / 86-02$

Publication date: April $30^{\text {th }} 2019$

\section{INTRODUCTION}

White lupin belongs to genus Lupinus, subfamily papilionaceae and family Leguminosae (also called Genisteae or Fabaceae), the third largest family [1,2]. White lupin was originated in the Balkin region of the northeast Mediterranean [3]. It has been traditionally cultivated for several thousands of years in the Mediterranean region and along the Nile valley where it has been originated. It is known to have been cultivated since ancient times in Greece, Italy, Egypt and Cyprus. It is also occasionally grown in Kenya, Tanzania, Zimbabwe, South Africa, Mauritius, United States, Brazil and Chile [6]. The genetic diversity of white lupine and other species of Lupinus could be characterized using morphological and agronomical attributes [1, $2 \& 10]$. The species of the genus Lupinus probably have a polyploid origin and they have different chromosomes numbers such as L. angustifolius $2 \mathrm{n}=40 ;$ L. mutabilis $2 \mathrm{n}=48 ;$ L. albus $2 \mathrm{n}=50 ;$ L. luteus $2 \mathrm{n}=52[2,11]$.

In Ethiopia it is exclusively produced by smallholder subsistence farmers, mainly for its food grain and soil fertility maintenance values. The local varieties being used by farmers have several undesirable characteristics, such as low yield potential, susceptibility to major diseases and high contents of alkaloids [1, 2, 4, 5 \& 7]. Therefore, there is a need to develop well adapted white lupin varieties with farmers' preferred traits including high grain yield, low alkaloids level and resistant to major lupin diseases. In Ethiopia, white lupin is locally known as Gibto. Different vernacular names were given to white lupin, such as Gibto in Ethiopia; Thermus in Greece; Tumus in Arabian countries and Termiyeor Acibakla in Turkey [1]. The local community in North-western Ethiopia gave the name Gibto is due to the legend that the crop was introduced to Ethiopia from Egypt, where the Amharic /local/ language name given to Egypt is 'Gibts'. White lupin is a predominant species produced by small scale farmers mainly in the Amhara region (Gojjam and Gondar) [8]. The crop is also produced in other parts of the country, such as in Benshangul Gumuz, S.N.N.P.R, Oromyia Regional States of Ethiopia in decreasing order of area coverage and total production $[2,9]$.

Moreover, research based information on the agro-morphological and genetic characteristics of the crop are not available to design future breeding strategies and promote the crop production and utilization. Such research gaps contributed to the prevailing major problems such as lack of early maturing, high-yielding, low/free alkaloid content varieties, and disease resistant cultivars. In Ethiopia, about 250 accessions are conserved [12, 13]; however; information is inadequate on the extent of its genetic variability and related genetic aspects. There is no information 
on the agronomic practice and use of L. albus in Bale Eco-region until 2019. Before any hybridization work, genetic diversity of the existing genotypes at morphological level needs to be known [2]. Moreover, evaluation of genetic variability is important to know the source of genes for particular trait within the available germplasms. Therefore, the current study was aimed to analyze genetic variability among 36 Ethiopian white lupin genotypes.

\section{METHODS}

The experiment was conducted during the Genna season (from March to June, 2017) at two locations namely: Research site of Madda Walabu University main campus (RSMWU), Robe and farmer's farm land of Gasera village in Bale Zone. As Bale Zone is known by its bimodal rainy seasons, there are two cropping seasons in the region Ganna (Kiremt) which ranges from March to June and Bona (Bega) ranges from July to December; crops which are planted on Kiremt season are collected in Bega season which is the dry period of the area. The two locations represent high lands region of Bale zone. The dominant soil type is pellic, vertisol and slightly acidic $(\mathrm{PH}=6.2)[2,14 \& 15]$.

\section{Experimental Materials}

Thirty six (36) white lupin accessions were used. The accessions were collected by Ethiopian Biodiversity Conservation (EBC) from diverse agro ecological locations of the country varying in altitude, rainfall, Latitude, Longitude and collection dates (accession passport), Table 1 [13].

\section{Experimental Design and Procedures}

Randomized Complete Block Design (RCBD) with three replications was used at both locations. Each replication contained 36 plots. The distance between plots was $50 \mathrm{~cm}$. Each genotype was sown in $1.20 \mathrm{~m}^{2}(1.20 \mathrm{~m}$ length $\mathrm{x} 1 \mathrm{~m}$ width) plots containing four rows with inter-row spacing of $30 \mathrm{~cm}$. Drilling mechanism was applied to provide seed hole along the row. Six seed holes per row with $20 \mathrm{~cm}$ gap hence were prepared. The layout and randomization was taken place as per the standard procedure set by Tadesse Adere and Temesgen Bedassa, 2019; Cochran and Cox, 1957 [2, 16]. For each genotype, two seeds per hole were thoroughly sown in the row, but later, ten days after germination, at true leaf stage, the plants in each hole of the row on the plots were thinned out as it should have about $20 \mathrm{~cm}$ gap from plant to plant. 24 plants per plot were maintained. However, the two middle rows alone were used for data collection for the parameters that were recorded as per plant to avoid border effect. Planting was carried out in the first week of March, 2017 for both locations. Three weeding activities and two hoeing practices were carried out and no fertilizer and chemicals were applied. All pertinent crop management practices were implemented with strict close supervision as per the recommendations adopted for the respective site. 
Table 1: Passport data (geographic origin and administrative units) of Ethiopian white lupin accessions

\begin{tabular}{|c|c|c|c|c|c|c|c|c|c|}
\hline № & Acc.\# & Region & Zone & District & Locality & Latitude* & Longitude & Altitude & C. Date \\
\hline 1 & AC. 24850 & Amara & Misrak & goncha & NA & $10-57-11-$ & 38-04-46- & 2496 & $25 / 12 / 2014$ \\
\hline 2 & AC. 26634 & Amara & Misrak & Gozamen & Layamba & $10-28-28-$ & $37-51-06-$ & 2883 & $15 / 02 / 2015$ \\
\hline 3 & AC. 26635 & Amara & Misrak & machakal & mahasar & $10-36-25-$ & $37-41-51-$ & 2793 & $3 / 02 / 2015$ \\
\hline 4 & AC. 26636 & Amara & Misrak & Senan & Yatad & $10-03-54-$ & $37-46-41-$ & 2975 & $3 / 05 / 2015$ \\
\hline 5 & AC. 26637 & Amara & Misrak & dabre & Zagab & $10-22-23-$ & $37-23-31-$ & 2163 & $3 / 09 / 2015$ \\
\hline 6 & AC. 26638 & Amara & Misrak & dabre & Atkaram & $10-18-44-$ & $37-29-37$ & 2225 & $09 / 09 / 2015$ \\
\hline 7 & AC. 26639 & Amara & Misrak & Baso & Wagaj & 10-09-78- & $37-39-56-$ & 2281 & $15 / 03 / 2014$ \\
\hline 8 & AC. 26640 & Amara & Misrak & Baso & Gutto & 10-09-53- & 37-43-13- & 2301 & $15 / 03 / 2014$ \\
\hline 9 & AC. 26641 & Amara & Misrak & yalamlam & wagaj & $10-09-46-$ & $37-43-27-$ & 2318 & $15 / 03 / 2014$ \\
\hline 10 & AC. 29054 & Amara & Agew & Dengla & Gerar & 11-19-03- & $36-44-43-$ & 2215 & $07 / 06 / 2008$ \\
\hline 11 & AC. 29055 & Amara & Agew & Dengla & woleta & 11-19-21- & $36-43-35-$ & 2122 & $07 / 06 / 2008$ \\
\hline 12 & AC. 29056 & Amara & Agew & Dangila & mehal & $11-21-40-$ & $36-46-06-$ & 2201 & $07 / 06 / 2008$ \\
\hline 13 & AC. 29057 & Amara & Agew & Dangila & IayAfat is & $11-20-38-$ & $36-45-26-$ & 2254 & $07 / 06 / 2008$ \\
\hline 14 & AC. 29058 & Amara & Agew & Dangila & IayAfat is & $11-20-12-$ & $36-46-04-$ & 2112 & $07 / 06 / 2008$ \\
\hline 15 & AC. 105001 & Amara & Mirab & Jabi & Woinma, & $10-45-00-$ & $37-06-00-$ & 2280 & $02 / 01 / 1978$ \\
\hline 16 & AC. 105002 & Amara & Debub & Este & Gudie & $11-37-00-$ & 38-01-00- & 2420 & 08/01/1979 \\
\hline 17 & AC.105006 & Amara & Mirab & Dembech & Debremek & $10-40-00-$ & $37-34-00-$ & 2430 & 09/01/1980 \\
\hline 18 & AC. 105007 & Amara & Misrak & Guzamn & about & $10-18-00-$ & $37-47-00-$ & 2430 & $15 / 03 / 1980$ \\
\hline 19 & AC.216014 & Amara & Misrak & Baso & $\mathrm{Aba}$ & 10-09-00- & $37-40-00-$ & 2320 & $05 / 01 / 1986$ \\
\hline 20 & AC.216015 & Amara & Misrak & Machake & Debre & $10-16-00-$ & $37-27-00-$ & 2280 & 05/01/1986 \\
\hline 21 & AC.216016 & Amara & Misrak & Machake & Genet $\mathrm{ab}$ & $10-23-00-$ & $37-27-00-$ & 2240 & $05 / 01 / 1986$ \\
\hline 22 & AC.225802 & SNNP & Semen & Dita & $5 \mathrm{~km}$ & $06-15-00-$ & $37-32-00-$ & 2800 & $07 / 01 / 1988$ \\
\hline 23 & AC. 239003 & Amara & Agew & Dangela & Smalta/Ge & 11-14-18- & $36-50-93-$ & 2190 & $10 / 01 / 1997$ \\
\hline 24 & AC. 239004 & Amara & Agew & Dangela & Zelesa/Ge & 11-30-29- & $36-51-58-$ & 2220 & $10 / 01 / 1997$ \\
\hline 25 & AC. 239005 & Amara & Agew & Dangela & Shangana & $11-09-82-$ & $36-5$ & 2360 & $10 / 01 / 1997$ \\
\hline 26 & AC. 239006 & Amara & Agew & Dangela & Ashewa & $-02-$ & $36-$ & 2400 & $10 / 01 / 1997$ \\
\hline 27 & AC. 239007 & Amara & Agew & Dangela & Ziguda/kid & $11-1$ & $36-$ & 2190 & $10 / 01 / 1997$ \\
\hline 28 & AC. 239017 & Amara & Debub & Dera & Amora & $11-55-24-$ & $37-54-21-$ & 2130 & $12 / 01 / 1997$ \\
\hline 29 & AC. 239046 & Amara & Mirab & Bure & Tilil & $10-50-56-$ & $37-01-88-$ & 2520 & $15 / 01 / 1997$ \\
\hline 30 & AC. 239047 & Amara & Mirab & Bure & Kurb & $10-49-65-$ & $37-02-45-$ & 2660 & $15 / 01 / 1997$ \\
\hline 31 & AC. 239048 & Amara & Mirab & Bure & Bradi & $10-47-88-$ & $37-03-24-$ & 2600 & $15 / 01 / 1997$ \\
\hline 32 & AC.239051 & Amara & Mirab & Bure & $157 \mathrm{~km}$ & $10-42-45-$ & $37-07-33-$ & 2120 & $15 / 01 / 1997$ \\
\hline 33 & AC.239054 & Amara & Mirab & Dembech & Mekelabo & 10-34-29- & $37-28-24-$ & 2210 & $15 / 01 / 1997$ \\
\hline 34 & AC. 239055 & Amara & Mirab & Dembech & $213 \mathrm{~km}$ & $10-32-86-$ & $37-30-61-$ & 2160 & $15 / 01 / 1997$ \\
\hline 35 & AC. 239057 & Amara & Misrak & Machake & Yewla & $10-25-07-$ & $37-33-93-$ & 2380 & $15 / 01 / 1997$ \\
\hline 36 & AC. 239059 & Amara & Misrak & Guzamn & $3 \mathrm{~km}$ & $10-18-35-$ & $37-44-07-$ & 2420 & $16 / 01 / 1997$ \\
\hline
\end{tabular}

Acc $\#=$ Accession number, NA=Not Available, $*=$ above sea level (m.a.s.1), C.Date= Collection Date. Source: [13].

\section{Data Collection}

The following data were collected during the experimental time both from the whole plot and from the sample plants that were randomly selected from the middle two rows of each plot.

Data on the whole plot basis

Days to emergence (DE): This was carried out by taking the total number of days from date of planting to when $50 \%$ of the seedlings in each plot appeared above the ground level.

Days to flowering initiation (DFI): This was determined by counting the number of days from date of sowing to date of some plants in each plot starts to bloom.

Days to flowering (DF): The actual count of number of days from the date of planting to the date on which about $50 \%$ of the plants in each plot produce flower.

Days to maturity (DM): Days to $90 \%$ physiological maturity was determined as the number of days from sowing to the date when the peduncles turned to yellow straw color. It was recorded when no green color remained on chaff and Peduncles of the plants.

Seed yield per plot (SYPL): 7\% moisture adjusted seed (dry seed yield) from the possible total harvestable rows of each experimental plot was recorded in grams.

Seed yield per hectare (SYH): It was the value of seed yield per plot converted to $\mathrm{kg} / \mathrm{ha}$.

Hundred Seeds weight (HSW): It was recorded as the weight in grams of 100 randomly taken and 7\% moistureadjusted seeds from each experimental plot.

Biomass yield per plot (BYPL): The above ground biomass yield at the time of harvesting was determined in grams from each experimental plot viz. from the net plot size. 
Data on plant (sample) basis

Data on plant basis were recorded for the following characters on five randomly taken plants from possibly harvestable rows of experimental unit (plot). These data were expressed as average of randomly taken five plants in each experimental plot viz. mean values of these measured samples were utilized to estimate the performance of each germplasm collection for the traits under consideration. Detailed accounts of each data type and collection methods are discussed hereunder.

Plant height at flowering (PHF):

Height of five randomly selected plants during flowering period from each experimental unit was measured in centimeter from the ground to top of the plant and the average height was recorded as plant height at flowering.

Number of primary branches (NPB):

Number of productive branches extending from the main stem was recorded on five randomly selected plants of each experimental plot and the means were recorded as number of primary branches per plant. Counting was done at the time when flowering was completely over and fruits were still green but old enough to judge that they would give seeds.

Number of secondary branches (NSB):

Number of branches extending from the primary branches was recorded on the same plants used to determine the number of primary branches from each plot and the means was recorded as number of secondary branches/plant.

Number of pods per node of the plant (NPN):

The total number of health pods was taken at physiological maturity from each node of five randomly selected plants, the average was used.

Number of pods per plant (NPP): the total number of health pods was taken at physiological maturity from five randomly selected plants

Pod length (PL): the average length of pod expressed in $\mathrm{cm}$ at physiological maturity from five randomly selected plants

Pod thickness (PT): the average thickness of pod expressed in $\mathrm{cm}$ at physiological maturity from five randomly selected plants

\section{Seed number per pods (SNPP):}

The number of seed was counted per pods from five randomly selected plants

Number of seeds per plant (NSP):

This was recorded as average total number of seed of five randomly taken plants from each experimental plot and the means were recorded as number of seed per plant.

Seed yield per plant (SYP):

The average weight in grams of seeds adjusted 7\% moisture content was obtained from five randomly selected plants on each plot.

Biomass yield per plant (BYP)

The above ground biomass yield at the time of harvesting was determined in grams from five randomly taken plants and their mean value was taken as biomass yield per plant. This value again converted to $\mathrm{kg} / \mathrm{ha}$

Harvest index (HI): It was recorded as the ratio of the moisture-adjusted seed yield per plant to the above ground biomass yield per plant in percentage as given by the formula;

$$
\text { Harvest Index }(\mathbf{H I})=\frac{\text { Moisture adjusted seed yield in gram per plant }}{\text { Biomass in gram per plant }}
$$

\section{Statistical procedures}

Before proceeding with the analysis of variance for each variable, homogeneity of error variances for combined analysis of the two locations was tested using the $F_{\max }$ test as given by [17]:

$$
\text { Fmax }=\frac{\text { Largest Mse }}{\text { Smallest Mse }} .
$$

This was tested at [(g-1) (r-1)] degree of freedom of mean square where Mse is mean square of error, $\mathrm{g}$ and $\mathrm{r}$ the number of genotypes and replications respectively. Then the table of the probability distribution of $F_{\max }$ was consulted. As a result, the calculated $F$ value must be less than the critical value at $5 \%$ of probability level with the specified degrees of freedom signifying the fact that the variances was homogenous and thus it was appropriate to proceed with ANOVA. 


\section{Analysis of variance}

To estimate the mean value of the recorded data and other differences among the varieties of both locations all measured variables were subjected to analysis of variance (ANOVA) as per the method of [17] using SAS Software program (Version 9.2). Test of mean separation was employed depending on the significance of analysis of variance. For significant difference among the treatments (the germplasm collections), mean separation was carried out using least significant difference (LSD) test at 5\% levels of significance; because the number of treatments (accessions) are many. The randomized complete block design (RCBD) analysis of variance was used to derive variance components as structured in Table 2 [16].

Table 2: RCBD analysis of variance and expected mean square

\begin{tabular}{llll}
\hline Source of variation & $\mathrm{Df}$ & Mean square & Expected mean square \\
\hline Replication & $\mathrm{r}-1$ & $\mathrm{~ms}_{\mathrm{r}}$ & $\sigma^{2} \mathrm{e}+\mathrm{g} \sigma^{2} \mathrm{r}$ \\
Genotypes & $\mathrm{g}-1$ & $\mathrm{~ms}_{\mathrm{g}}$ & $\sigma^{2} \mathrm{e}+\mathrm{r} \sigma^{2} \mathrm{~g}$ \\
Error & $(\mathrm{r}-1)(\mathrm{g}-1)$ & $\mathrm{ms}_{\mathrm{e}}$ & $\sigma^{2} \mathrm{e}$ \\
\hline
\end{tabular}

Where, $\mathrm{r}=$ number of replications; $\mathrm{ms}_{\mathrm{r}}=$ mean square due to replications; $\mathrm{g}=$ number of genotypes; $\mathrm{ms}_{\mathrm{g}}=\mathrm{mean}$ square due to genotypes; $\mathrm{ms}_{\mathrm{e}}=$ mean square of error; $\sigma^{2} \mathrm{~g}, \sigma^{2} \mathrm{r}$ and $\sigma^{2} \mathrm{e}$ are variances due to genotype, replication and error, respectively.

RCBD ANOVA was computed using the following model: $Y \mathrm{ij}=\mu+\mathrm{rj}+\mathrm{gi}+\varepsilon \mathrm{ij}$

Where, $\mathrm{Yij}=$ the response of trait $\mathrm{Y}$ in the $\mathrm{i}^{\text {th }}$ genotype and the $\mathrm{j}^{\text {th }}$ replication; $\mu=$ the grand mean of trait $\mathrm{Y}$ $\mathrm{rj}=$ the effect of the $\mathrm{j}^{\text {th }}$ replication; $\mathrm{gi}=$ the effect of the $\mathrm{i}^{\text {th }}$ genotype; $\varepsilon \mathrm{ij}=$ experimental error effect

\section{Phenotypic and genotypic variability}

The variability present in the genotype was estimated by simple measure, namely range, mean, standard error, phenotypic and genotypic variance and coefficient of variation. The phenotypic and genotypic variance and coefficient of variation were estimated according to the methods suggested by [18] as follows:

Phenotypic variance $\left(\sigma^{2} \mathrm{p}\right)=\sigma^{2} \mathrm{~g}+\sigma^{2} \mathrm{e} \quad$ Where $\quad \sigma^{2} \mathrm{~g}=\frac{\text { Msg-Mse }}{\mathrm{r}}$

Where: $\sigma^{2} p=$ Phenotypic variance; $\sigma^{2} e=$ Environmental (error) variance; $\sigma^{2} g=$ Genotypic

Variance $M s e=$ mean square of error; $M s g=$ mean square of genotypes; $r=$ Number of replication.

The genotypic and phenotypic coefficients of variability were undertaken according to the formulae of [19].

Phenotypic coefficient of variation, $\mathrm{PCV}=\frac{\sqrt{\sigma^{2} \mathrm{p}}}{\mathrm{x}} \mathrm{x} 100=(\sigma \mathrm{p} / \mathrm{x}) \times 100$

Genotypic coefficient of variation, $\mathrm{GCV}=\frac{\sqrt{\sigma^{2} g}}{X} x 100=(\sigma \mathrm{g} / \mathrm{x}) \times 100$

Where $\mathrm{x}=$ grand mean for the character $\mathrm{X} ; \sigma \mathrm{g}$ and $\sigma \mathrm{p}$ are genotypic and phenotypic standard deviations, respectively.

\section{Estimate of broad sense heritability}

Heritability $\left(\mathrm{h}^{2}\right)$ in broad sense for all characters at the two locations was computed using the formula adopted by [20] and [21] as: $\mathrm{h}^{2}=\sigma^{2} \mathrm{~g} / \sigma^{2} \mathrm{p}$ Where: $\quad \sigma^{2} \mathrm{~g}=$ genotypic variance, $\quad \sigma^{2} P=$ phenotypic variance, $\quad \sigma^{2} \mathrm{e}=$ error variance. Percentage broad sense heritability $\left(\mathrm{h}^{2}\right)=\left[\sigma^{2} \mathrm{~g} / \sigma^{2} \mathrm{p}\right]$ x 100 . Heritability percentage was categorized as suggested by [22] as follows.

\section{Estimation of expected genetic advance}

$$
0-30 \%=\text { Low } 30-60 \%=\text { Moderate; }>60 \%=\text { High }
$$

Genetic advance as part of mean (GA) for each character at the two locations, assuming selection of the superior $5 \%$ of the genotypes, was estimated using the formula adopted from $[23,20]$ :

$\mathrm{GA}=(\mathrm{k}) *(\sigma \mathrm{p}) *\left(\mathrm{~h}^{2}\right)$ and $\mathrm{GA}($ as $\%$ of the mean $)=\left[\frac{(\mathrm{GA})}{\mathrm{x}}\right] \mathrm{x} 100$

Where: $\mathrm{k}=$ selection differential $(\mathrm{k}=2.06$ at $5 \%$ selection intensity)

$$
\sigma \mathrm{p}=\text { phenotypic standard deviation, } \mathrm{h}^{2}=\text { heritability, } x \quad \text { Grand mean }
$$

\section{Estimation of phenotypic and genotypic correlations}

Phenotypic and genotypic correlations between yield and yield related traits were estimated using the method described by [23] as: $\quad \operatorname{rpxy}=\frac{\text { covpxy }}{\sqrt{\sigma^{2} \mathrm{px} \cdot \sigma^{2} \mathrm{py}}}$

Where: $r p x y=$ phenotypic correlation coefficient between character $\mathrm{x}$ and $\mathrm{y}$ COV p xy $=$ phenotypic covariance between character $\mathrm{x}$ and $\mathrm{y} ; \sigma^{2} p x=$ phenotypic variance for character $\mathrm{x}$

$$
\sigma^{2} p y=\text { phenotypic variance for character } \mathrm{y} ; \quad \operatorname{rgxy}=\frac{\operatorname{covgxy}}{\sqrt{\sigma^{2} g x \cdot \sigma^{2} g y}}
$$

Where; $r g x y=$ genotypic correlation coefficient between character $\mathrm{x}$ and $\mathrm{y}$ COVgxy = genotypic covariance between character $\mathrm{x}$ and $\mathrm{y}$ 
$\sigma^{2} g x=$ genotypic variance for character $\mathrm{x}, \sigma^{2} g y=$ genotypic variance for character $\mathrm{y}$

The coefficient of correlation at phenotypic level was tested for their significance by comparing the values of correlation coefficient with tabulated r-value at g-2 degree of freedom, where ' $\mathrm{g}$ ' is number of genotypes (the germplasm accessions in this case). However, the coefficient of correlations at genotypic level was tested for their significance using the formula described by [24] described as $t=\frac{(r g x y)}{\operatorname{SErgxy}}$. The calculated ' $\mathrm{t}$ ' value was compared with the tabulated ' $t$ ' value at $g-2$ degree of freedom at $5 \%$ level of significance. Where, $g=$ number of genotypes, $\operatorname{rgxy}=$ genotypic correlation coefficient and SErgxy = standard error of genotypic correlation coefficient between character $\mathrm{x}$ and $\mathrm{y}$ which were calculated as:

$S E g x y=\frac{\sqrt{\left(1-r^{2} g x y\right)}}{2 h x * h y} \quad$ Where: $\mathrm{h}_{\mathrm{x}}=$ Heritability value of character $\mathrm{x}$ and $\mathrm{h}_{\mathrm{y}}=$ heritability value of character $\mathrm{y}$

\section{RESULTS}

The estimated range, mean and standard error of the studied 18 characters at both locations, Research site of Madda Walabu University, Robe and at Gasera farmer's farm land are shown in Tables 3.

Table 3: Estimates of minimum, mean, maximum and standard errors values for the 18 traits of the tested 36 white lupin genotypes

\begin{tabular}{llllllll}
\hline Traits & $\begin{array}{l}\text { Min } \\
\text { value }\end{array}$ & $\begin{array}{l}\text { Min performing } \\
\text { accession }\end{array}$ & $\begin{array}{l}\text { Overall } \\
\text { Mean value }\end{array}$ & $\begin{array}{l}\text { Max } \\
\text { value }\end{array}$ & $\begin{array}{l}\text { Max performing } \\
\text { accession }\end{array}$ & MSg & SE \\
\hline DE & 6.67 & AC 29054 & 10.08 & 15 & AC 225802 & $25.86^{*}$ & \pm 0.43 \\
DFI & 57.00 & AC 29055 & 71.84 & 108 & AC 26635 & $1134.45^{* *}$ & \pm 2.00 \\
DF & 66 & AC 239017 & 82.97 & 121.5 & AC 26635 & $1530.09 * *$ & \pm 2.05 \\
PHF & 56 & AC 29054 & 82.22 & 137.83 & AC 29057 & $3140.54 * *$ & \pm 2.96 \\
NPB & 4 & AC 29058 & 4.23 & 5.13 & A C239004 & 23.19 ns & \pm 0.20 \\
NSB & 4.83 & AC 26635 & 12.53 & 23.17 & AC 26640 & $124.82^{* *}$ & \pm 0.60 \\
PL & 6 & AC 239046 & 10.23 & 13 & AC 105006 & $27.47 * *$ & \pm 0.18 \\
PT & 3.1 & AC 26635 & 3.89 & 4.5 & AC 29055 & 0.773 ns & \pm 0.04 \\
NPP & 19 & AC 239048 & 54.13 & 103.33 & AC 216014 & $5141.128 * *$ & \pm 3.05 \\
SNPP & 3.00 & AC 29058 & 4.70 & 7 & AC 239048 & $8.733 * *$ & \pm 0.11 \\
NSP & 71 & AC 239005 & 195.21 & 393.67 & AC 26640 & $51855.88^{* *}$ & \pm 7.89 \\
DM & 170.33 & AC 239054 & 194.84 & 231.33 & AC 216015 & $1429.294 * * *$ & \pm 3.16 \\
SYP & 28.64 & AC 239051 & 102.33 & 222.87 & AC 239055 & $35412.43 * *$ & \pm 5.60 \\
SYPL & 98.84 & AC 239051 & 486.92 & 1194.79 & AC 26640 & $732105.00^{* *}$ & \pm 9.00 \\
SYH & 787.6 & AC 239051 & 3982.29 & 8196.8 & AC 26634 & $48658799.00^{* *}$ & \pm 9.13 \\
HSW & 9.35 & AC 239051 & 30.48 & 46.8 & AC 216014 & $21194.10^{* * *}$ & \pm 0.91 \\
BYPL & 1.03 & AC 239054 & 1.93 & 3.45 & AC 26640 & $2.55^{* *}$ & \pm 0.12 \\
HI & 25.66 & AC 216915 & 65.13 & 91.8 & AC29055 & $3193.58 * *$ & \pm 1.80 \\
\hline
\end{tabular}

$*=$ significant, $* *=$ highly significant, $* * * *=$ very highly significant $={ }^{\mathrm{ns}}=$ non-significant at $\mathrm{P}$ value $5 \%, 1 \% \&$ $0.1 \%$; Min and max stand for minimum and maximum respectively Msg $=$ Mean Square of genotypes. DE $=$ Days to Emergence, $\mathrm{DFI}=$ Days to flowering initiation, $\mathrm{DF}=$ Days to $50 \%$ flowering, $\mathrm{PHF}=\mathrm{Plan}$ height at flowering in centimeter, $\mathrm{NPB}=$ number of primary branches per plant, $\mathrm{NSB}=$ number of secondary branches per plant. $\mathrm{PL}=$ Pod length in centimeter, PT $=$ Pod thickness in centimeter, NPP $=$ Number of pod per plant, SNPP $=$ Seed number per pod, NSP =number of seed per plant, DM = Days to maturity, SYP= Seed yield per plant in gram, $\mathrm{SYPL}=$ Seed yield per plot $(\mathrm{g}), \mathrm{SYH}=$ Seed yield per Hectare $(\mathrm{Kg}), \mathrm{HSW}=$ hundred seed weight $(\mathrm{g}), \mathrm{BYPL}=\mathrm{BiomasS}$ Yield per plot $(\mathrm{Kg}), \mathrm{HI}=$ Harvest index in percentage.

Wide ranges were recorded for almost all studied traits starting from days to emergence to days to maturity, including plant height, seed number per plant, number of pod per plant, hundred seed weight and numbers of secondary branches per plant except pod length, and numbers of primary branches per plant. The result of combined analysis of variance for each studied trait for both locations showed significance $(p<0.05)$, highly significant $(\mathrm{P}<0.01)$ and very highly significant $(\mathrm{P}<0.001)$ differences among the accessions for most of the characters considered at both Robe and Gasera (Table 3). However, two traits, number of primary branches (NPB) and pod thickness (PT) at both locations and DE at Gasera alone showed non-significant $(\mathrm{p}>0.05)$ differences and, hence, these parameters were excluded from the variability test.

The presence of variability was observed in the analysis or variances, ANOVA, for experiments at both locations. The minimum seed yield per plant, SYP, (28.34g) was exhibited by the germplasm AC.239055 and the maximum $(222.87 \mathrm{~g}$ ) was by AC.239051 for both locations. Broad range of variability was observed, as it was exhibited, by each germplasm collection based on its overall mean performance, Table 5 . Although the number of days required for all accessions to start flowering ranges from 51 to 108 days, only half of the tested accessions reached flowering much earlier than the overall mean performance value of days to flowering initiation (DFI) 
(71.8 days), Table 5. The minimum days to flowering initiation was exhibited by the accession AC.29055 whereas the accession AC.26635 took the maximum (longest) days to start flowering, at both locations, Table 5. The genotype AC26635 showed the maximum grand mean performance of days to start flowering but, location wise it took shorter time (96 days) to start flowering at RSMWU than at Gasera (100days) due to different soil moistures. On the other hand, three of the accessions, specifically, AC239005, AC 216015 and AC105006 took statistically nearly similar number of days to overall population mean value (71.8days). Generally, all the tested accessions required 51 to 108 days to pass through their vegetative growth. The range and mean values in this study suggest the existence of sufficient variability among the tested white lupin genotypes for the majority of the characters studied and their considerable potential in the improvement of Lupinus albus L.

Table 4: Mean squares from analysis of variance for the 18 characters of 36 White lupin landraces

\begin{tabular}{llllllll}
\hline Traits & $M s g$ & $M s l$ & \multicolumn{1}{c}{$M s r$} & \multicolumn{1}{c}{ Mse } & Mean & CV (\%) & LSD\% \\
\hline Df & 35 & 1 & 2 & - & - & - & - \\
DE & $25.86^{* *}$ & $27.44^{* *}$ & $0.087^{\mathrm{ns}}$ & 1.75 & 10.08 & 13.13 & 0.35 \\
DFI & $1134.45^{* *}$ & $287.04^{*}$ & $0.12^{\mathrm{ns}}$ & 39.77 & 71.84 & 8.77 & 1.69 \\
DF & $1530.09^{* *}$ & $47.22^{*}$ & $1.31^{\mathrm{ns}}$ & 51.14 & 82.97 & 8.62 & 1.92 \\
PHF & $3140.54^{* *}$ & $3105.37^{* *}$ & $57.64^{*}$ & 86.96 & 82.22 & 11.34 & 2.50 \\
NPB & $23.19^{\mathrm{ns}}$ & $0.00^{\mathrm{ns}}$ & $0.004^{\mathrm{ns}}$ & 0.58 & 4.23 & 10.78 & 0.20 \\
NSB & $124.82^{* *}$ & $0.018^{\mathrm{ns}}$ & $0.014^{\mathrm{ns}}$ & 5.18 & 12.53 & 5.18 & 0.61 \\
PL & $27.47^{* *}$ & $6.16^{* *}$ & $0.35^{\mathrm{ns}}$ & 0.23 & 10.23 & 4.74 & 0.13 \\
PT & $0.773^{\mathrm{ns}}$ & $0.003^{\mathrm{ns}}$ & $0.000^{\mathrm{ns}}$ & 0.019 & 3.89 & 3.33 & 0.04 \\
NPP & $5141.128^{* *}$ & $40.907^{\mathrm{ns}}$ & $9.590^{\mathrm{ns}}$ & 92.28 & 54.13 & 17.74 & 2.58 \\
SNPP & $8.733^{* *}$ & $0.667^{\mathrm{ns}}$ & $0.000^{\mathrm{ns}}$ & 0.137 & 4.70 & 7.89 & 0.09 \\
NSP & $51855.88^{* *}$ & $6.000^{\mathrm{ns}}$ & $7.907^{\mathrm{ns}}$ & 890.83 & 195.21 & 15.28 & 8.03 \\
DM & $1429.294^{* *}$ & $25.351^{\mathrm{ns}}$ & $475.587^{* *}$ & 16.354 & 194.84 & 2.07 & 1.09 \\
SYP & $35412.43^{* *}$ & $27481.10^{* *}$ & $0.471^{\mathrm{ns}}$ & 346.54 & 102.33 & 18.19 & 5.00 \\
SYPL & $732105.00^{* *}$ & $4283.31^{*}$ & $0.46^{\mathrm{ns}}$ & 14960.17 & 486.92 & 25.12 & 32.90 \\
SYH & $48658799.00^{* *}$ & $5641.00^{\mathrm{ns}}$ & $0.000^{\mathrm{ns}}$ & 983766.00 & 3982.29 & 24.90 & 266.85 \\
HSW & $21194.10^{* *}$ & $2723.56^{*}$ & $0.431^{\mathrm{ns}}$ & 1269.22 & 30.48 & 11.68 & 9.58 \\
BYPL & $2.55^{* *}$ & $0.019^{\mathrm{ns}}$ & $0.015^{*}$ & 0.15 & 1.93 & 19.99 & 0.104 \\
HI & $3193.58^{* *}$ & $2175.574^{*}$ & $441.66^{*}$ & 438.56 & 65.13 & 30.85 & 5.63 \\
\hline
\end{tabular}

$*=$ significant, $* *=$ highly significant, $* * * *=$ very highly significant $=$ and ${ }^{\mathrm{ns}}=$ non-significant at $\mathrm{P}$ value $=0.05$, 0.01 and 0.001. $D f=$ Degree of freedom, $M s r=$ Mean square of replication, $M s g=$ Mean square of genotype, $M s l=$ Mean square of location, $M s e=$ Mean square of error. DE= Days to Emergence, DFI= Days to flowering initiation, $\mathrm{DF}=$ Days to $50 \%$ flowering, $\mathrm{PHF}=\mathrm{Plan}$ height at flowering in centimeter, $\mathrm{NPB}=$ number of primary branches per plant, $\mathrm{NSB}=$ number of secondary branches per plant. $\mathrm{PL}=$ Pod length in centimeter, $\mathrm{PT}=$ Pod thickness in centimeter, $\mathrm{NPP}=$ Number of pod per plant, $\mathrm{SNPP}=$ Seed number per pod, NSP= number of seed per plant, $\mathrm{DM}=$ Days to maturity, $\mathrm{SYP}=$ Seed yield per plant in gram, $\mathrm{SYPL}=$ Seed yield per plot $(\mathrm{g}), \mathrm{SYH}=\mathrm{Seed}$ yield per Hectare $(\mathrm{Kg}), \mathrm{HSW}=$ hundred seed weight $(\mathrm{g}), \mathrm{BYPL}=$ Biomass Yield per plot $(\mathrm{Kg}), \mathrm{HI}=$ Harvest index in percentage. 
Table 5: Mean performances of the 36 tested Lupinus albus L. accessions with 18 traits (Result of Combined

\begin{tabular}{|c|c|c|c|c|c|c|c|c|c|c|c|c|c|c|c|c|c|c|c|}
\hline \multicolumn{20}{|c|}{ analysis) } \\
\hline Acc & $\mathrm{DE}$ & DFI & $\mathrm{DF}$ & PHF & NPB & NSB & PL & PT & NPP & SNPP & NSP & DM & SYP & SYP1 & SYH & HSW & BYP1 & $\mathrm{HI}$ & SE \\
\hline AC. 24850 & 12 & 64.2 & 87.33 & 61.5 & 9 & 16 & 12 & 4.1 & 41.67 & 6.5 & 161.33 & 199.33 & 74.54 & 472.32 & 3897.6 & 34.25 & 1.9 & 73.15 & 0.81 \\
\hline AC. 26634 & 9 & 67.7 & 81 & 93 & 7 & 9.67 & 6.08 & 4.25 & 102.5 & 3 & 286.17 & 182.17 & 128.99 & 1002.9 & 8196.8 & 35.13 & 3.18 & 83.46 & 29.3 \\
\hline AC. 26635 & 14.33 & 98.2 & 121.5 & 59.83 & 4.05 & 4.83 & 6.67 & 3.1 & 36 & 6.33 & 173.83 & 179.83 & 68.68 & 467.31 & 3827.3 & 15.72 & 1.26 & 61.59 & 134.9 \\
\hline AC. 26636 & 9.83 & 93 & 112.83 & 76.5 & 4.33 & 8 & 8.17 & 8.2 & 87.67 & 4.33 & 218 & 205.33 & 101.67 & 791.84 & 6382.4 & 22.63 & 2.12 & 84.28 & 1.83 \\
\hline AC. 26637 & 7.67 & 69.3 & 82. & 123.67 & 9.67 & 19.83 & 10.33 & 4 & 73.33 & 5.5 & 366.83 & 182 & 198.77 & 1193.03 & 9711.0 & 42.28 & 3.34 & 90.97 & 155.7 \\
\hline AC. 26638 & 8.67 & 62 & 71.33 & 75.17 & 7.67 & 10.5 & 12 & 3.87 & 41.67 & 5.83 & 226.67 & 179.67 & 95.58 & 509 & 4133.8 & 30.85 & 1.1 & 63.6 & 167.9 \\
\hline AC. 26639 & 8.67 & 69.7 & 76 & 96.83 & 5.33 & 8.83 & 10.5 & 4.38 & 88 & 4.33 & 358.33 & 201.33 & 173.97 & 851.53 & 7035.3 & 34.9 & 2.51 & 79.29 & 100.6 \\
\hline AC. 26640 & 11.83 & 84.8 & 95.5 & 112.67 & 8.33 & 23.17 & 8.5 & 4.33 & 127 & 3.67 & 393.67 & 213.5 & 195.53 & 1194.8 & 9503.3 & 39.73 & 3.45 & 86.1 & 37.79 \\
\hline AC. 26641 & 11.67 & 97.7 & 117.33 & 103.17 & 7.33 & 15.17 & 6.02 & 4.05 & 102.8 & 3 & 304.83 & 222 & 168.57 & 913.4 & 7491.8 & 31.28 & 2.75 & 66.66 & 56.53 \\
\hline AC. 29054 & 6.67 & 85.7 & 102.33 & 56 & 4.53 & 6 & 12.17 & 4 & 34.33 & 5.5 & 123 & 179.33 & 58.5 & 191 & 1455.8 & 12.35 & 1.13 & 27.94 & 0.35 \\
\hline AC. 29055 & 10 & 57 & 68.33 & 82.5 & 8 & 11 & 12 & 5.5 & 84 & 4 & 332 & 182.83 & 183.7 & 912.2 & 7465.1 & 36.4 & 2.75 & 91.8 & 0.27 \\
\hline AC. 29056 & 9 & 66.7 & 78.33 & 68 & 6 & 13 & 12.03 & 4 & 68 & 6.17 & 262 & 184.83 & 116.6 & 729.6 & 6168.8 & 42.9 & 2.01 & 87.36 & 0.14 \\
\hline AC. 29057 & 10 & 78.7 & 87.33 & 137.83 & 6 & 14 & 12 & 4 & 90.67 & 4 & 200.5 & 185.5 & 104.5 & 437 & 3169.7 & 36.3 & 1.2 & 72.58 & 0.36 \\
\hline AC. 29058 & 9 & 60.7 & 69.67 & 71.33 & 4 & 7 & 8 & 4.2 & 31.67 & 3 & 91.67 & 207.67 & 49.71 & 145.36 & 1170.7 & 24.4 & 1.8 & 56.67 & 0.28 \\
\hline AC. 105001 & 143 & 57.7 & 72 & 114.83 & 9 & 22 & 11.5 & 4 & 79.33 & 4 & 319 & 180.67 & 181.51 & 91906 & 7466.5 & 407 & 291 & 86.38 & 0.25 \\
\hline AC. 105002 & 7.67 & 95.3 & 110.7 & 62.67 & 10 & 14 & 12 & 3.7 & 26.67 & 6 & 80 & 223.33 & 44.71 & 128.65 & 1035.5 & 34.4 & 2 & 32.39 & 0.5 \\
\hline AC. 105006 & 12 & 71 & 79.33 & 61 & 6 & 10 & 13 & 4 & 32.67 & 5 & 152 & 187 & 60 & 218 & 1762.6 & 44.35 & 1.84 & 70.4 & 0.55 \\
\hline AC. 105007 & 8 & 84.3 & 91 & 68 & 7 & 17 & 8 & 4.7 & 44 & 3 & 116 & 196.33 & 50.47 & 170.52 & 1381.3 & 46.25 & 1.8 & 47.29 & 0.2 \\
\hline AC. 216014 & 10 & 58.7 & 79 & 123 & 7 & 9 & 10 & 4.3 & 103.3 & 3 & 301 & 208 & 167.28 & 827.72 & 6791.7 & 468 & 2.39 & 81.88 & 30.33 \\
\hline AC. 216015 & 9 & 71.3 & 80 & 66.5 & 8 & 18 & 8 & 4.3 & 36 & 4 & 102 & 231.33 & 41.18 & 122.63 & 1476.4 & 42.25 & 1.6 & 25.66 & 0.23 \\
\hline AC. 216016 & 8 & 63 & 71 & 80.33 & 8 & 15 & 7.33 & 4.5 & 60 & 4 & 221 & 187.33 & 115.54 & 651.84 & 5430 & 43.35 & 2.28 & 87.22 & 0.27 \\
\hline AC. 225802 & 15 & 66.3 & 74 & 66.17 & 5 & 9 & 12 & 4.3 & 39 & 7 & 215 & 218.33 & 90.2 & 388.37 & 3253.3 & 42.4 & 1.16 & 72.8 & 0.39 \\
\hline AC. 239003 & 10 & 108 & 116 & 99.5 & 8 & 20 & 9 & 3.9 & 51 & 5 & 149 & 192.33 & 51.03 & 161.71 & 1311.2 & 38.3 & 1.7 & 42.01 & 0.33 \\
\hline AC. 239004 & 10 & 59 & 73 & 66 & 6.02 & 14 & 10 & 4.5 & 23 & 5 & 112 & 178.5 & 36 & 109 & 872.0 & 40.2 & 1.99 & 40.4 & 0.17 \\
\hline AC. 239005 & 12 & 70 & 79 & 66 & 7 & 12 & 12 & 4 & 27 & 6 & 71 & 214.33 & 29.23 & 108.3 & 865.0 & 9.4 & 1.5 & 26.26 & 0.2 \\
\hline AC. 239006 & 12 & 87 & 97 & 62 & 6 & 9.67 & 11.5 & 4.1 & 46 & 5 & 120 & 192.33 & 51.8 & 125.8 & 1012.5 & 16.3 & 1.2 & 52.65 & 0.16 \\
\hline AC. 239007 & 8 & 68 & 73 & 69 & 7 & 14 & 12 & 4.1 & 34 & 5 & 169 & 187.67 & 70.3 & 242.8 & 1986.2 & 18.25 & 2.2 & 59.8 & 0.13 \\
\hline AC. 239017 & 10 & 58 & 66 & 85.5 & 6.02 & 13 & 12 & 4.1 & 28 & 5 & 118 & 172.83 & 38.4 & 135.4 & 1090.5 & 13.95 & 2.02 & 64.1 & 0.24 \\
\hline AC. 239046 & 12 & 67 & 73 & 107.5 & 9 & 17 & 6 & 4.7 & 67 & 3 & 200 & 210.33 & 91.44 & 589.64 & 4876.7 & 18.3 & 1.78 & 85.7 & 0.19 \\
\hline AC. 239047 & 9 & 78 & 84 & 107.33 & 7 & 15 & 12 & 4.3 & 79 & 4 & 317 & 205.83 & 171.5 & 984.2 & 8165.1 & 32.4 & 2.31 & 88.78 & 0.3 \\
\hline AC. 239048 & 11 & 62 & 70 & 58.5 & 8 & 12 & 12 & 4 & 19 & 7 & 130 & 188.33 & 62 & 237 & 1938.2 & 20.75 & 1.3 & 66.6 & 0.16 \\
\hline AC. 239051 & 11.67 & 65 & 75 & 60.5 & 6 & 9 & 10 & 4.4 & 24 & 4 & 92 & 189.83 & 28.64 & 98.84 & 787.6 & 9.35 & 1.78 & 34.34 & 0.11 \\
\hline AC. 239054 & 6.83 & 61.5 & 67.5 & 62.5 & 5 & 7 & 10 & 4 & 21 & 6 & 123 & 170.33 & 59.7 & 331.4 & 2625.7 & 34.3 & 1.03 & 65.23 & 0.22 \\
\hline AC. 239055 & 8 & 57 & 68 & 77.5 & 5 & 7 & 12.5 & 4.2 & 38 & 5 & 188 & 184.33 & 222.87 & 427.4 & 3525 & 32.45 & 1.11 & 84.57 & 0.25 \\
\hline AC. 239057 & 9.17 & 65.5 & 70 & 100.5 & 7 & 10 & 10 & 4.6 & 40 & 4 & 154 & 199.77 & 67.1 & 638.6 & 5284.7 & 24.35 & 1.8 & 70.45 & 0.34 \\
\hline AC. 239059 & 11.17 & 60 & 67.8 & 66 & 6 & 10 & 10 & 4.4 & 21.67 & 4.33 & 79.83 & 190.5 & 33.55 & 101.09 & 814.5 & 10.12 & 1.37 & 34.37 & 0.75 \\
\hline$(\mathrm{X})$ & 10.08 & 71.8 & 82.97 & 82.22 & 4.23 & 12.5 & 10.23 & 3.89 & 54.13 & 4.71 & 195.2 & 194.86 & 102.33 & 486.92 & 3982.2 & 30.49 & 1.93 & 65.13 & \\
\hline $\mathrm{SE}$ & 0.43 & 2 & 2.05 & 2.96 & 0.2 & 0.6 & 0.18 & 0.04 & 3.05 & 0.11 & 7.89 & 3.16 & 5.6 & 9 & 9.13 & 0.91 & 0.12 & 1.8 & \\
\hline CV\% & 4.26 & 2.79 & 2.47 & 3.60 & 2.86 & 4.78 & 1.78 & 0.92 & 5.63 & 2.33 & 4.04 & 1.62 & 5.78 & 1.85 & 0.23 & 2.98 & 6.22 & 2.76 & \\
\hline D & 35 & 160 & $10 ?$ & 251 & 20 & 61 & 13 & 004 & 258 & 000 & 803 & . & 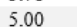 & 2.90 & 26685 & 9.58 & 10 & 63 & \\
\hline
\end{tabular}

$(\mathrm{X})=$ Overall Mean, $\mathrm{SE}=$ Standard Error, $\mathrm{CV} \%=$ Coefficient of Variation in Percentage, LSD $=$ Least Significant Difference, $\mathrm{DE}=$ Days to Emergence, $\mathrm{DFI}=$ Days to flowering initiation, $\mathrm{DF}=$ Days to $50 \%$ flowering, $\mathrm{PHF}=\mathrm{Plan}$ height at flowering in centimeter, NPB = number of primary branches per plant, NSB = number of secondary branches per plant. $\mathrm{PL}=$ Pod length in centimeter, $\mathrm{PT}=$ Pod thickness in centimeter, NPP $=$ Number of pod per plant, SNPP =Seed number per pod, NSP =number of seed per plant, DM = Days to maturity, SYP= Seed yield per plant in gram, SYPL $=$ Seed yield per plot $(\mathrm{g}), \mathrm{SYH}=$ Seed yield per Hectare $(\mathrm{Kg}), \mathrm{HSW}=$ hundred seed weight $(\mathrm{g}), \mathrm{BYPL}=$ Biomass Yield per plot $(\mathrm{Kg}), \mathrm{HI}=$ Harvest index in percentage.

\section{Estimation of phenotypic and genotypic coefficient of variation}

The combined analysis over the two locations of this research revealed relatively the highest value of PCV (174.36) and GCV (170.39) were exhibited by the trait hundred seed weight, HSW whereas the lowest PCV and GCV were exhibited by the trait DM as $15.43 \%$ and $11.13 \%$ respectively, Table 6 . About $11(61.11 \%)$ of the studied traits showed very high (50.39-170.39) GCV and the other $33.33 \%$ also showed high (28 - 46.34) GCV which were the indicators of the genetic variations Table 6 . 
Table 6: Estimates of grand mean value, variances at genotypic and phenotypic; coefficient of variation at genotypic and phenotypic level; heritability in broad sense $\left(\mathrm{h}^{2} \%\right)$, genetic advance in absolute (GA) and percent of mean (GAM) for 18 traits of Lupinus albus $\mathrm{L}$.

\begin{tabular}{l|llllllllll}
\hline & Grand & & & & & & & & \\
Traits & Mean & $\sigma^{2} \mathrm{~g}$ & $\sigma^{2} \mathrm{e}$ & $\sigma^{2} \mathrm{P}$ & $\mathrm{PCV} \%$ & $\mathrm{GCV} \%$ & $\mathrm{~W}$ & $\mathrm{~h}^{2 \%}$ & $\mathrm{GA}$ & $\mathrm{GAM}$ \\
\hline DE & 10.08 & 8.03 & 1.75 & 9.78 & 31.02 & 30.96 & 0.06 & $82 \%$ & 5.27 & 52.28 \\
DFI & 71.84 & 3698.00 & 39.77 & 3737.77 & 85.10 & 84.64 & 0.46 & $98 \%$ & 123.18 & 171.44 \\
DF & 82.97 & 492.98 & 51.15 & 544.13 & 28.11 & 26.76 & 1.35 & $90 \%$ & 43.45 & 52.31 \\
PHF & 82.22 & 1017.86 & 86.96 & 1104.82 & 40.42 & 38.80 & 1.62 & $92 \%$ & 62.87 & 76.46 \\
NPB & 4.23 & 7.54 & 0.58 & 8.12 & 65.36 & 64.92 & 0.44 & $93 \%$ & 5.44 & 128.50 \\
NSB & 12.53 & 39.88 & 5.18 & 45.06 & 53.57 & 50.39 & 3.18 & $88 \%$ & 12.21 & 97.47 \\
PL & 10.23 & 9.08 & 0.24 & 9.32 & 29.84 & 29.45 & 0.39 & $97 \%$ & 6.08 & 59.45 \\
PT & 3.89 & 0.25 & 0.02 & 0.27 & 13.35 & 12.85 & 0.50 & $93 \%$ & 0.99 & 25.44 \\
NPP & 54.13 & 1682.94 & 92.29 & 1775.23 & 77.83 & 75.78 & 2.05 & $94 \%$ & 82.12 & 151.68 \\
SNPP & 4.70 & 2.86 & 0.14 & 3.01 & 36.91 & 35.98 & 0.93 & $95 \%$ & 3.38 & 72.06 \\
NSP & 195.21 & 16988.05 & 890.83 & 17878.88 & 68.49 & 66.76 & 1.73 & $95 \%$ & 261.21 & 133.79 \\
DM & 194.84 & 470.98 & 16.35 & 487.33 & 15.43 & 11.13 & 4.30 & $96 \%$ & 43.60 & 22.37 \\
SYP & 102.33 & 11688.01 & 346.54 & 12035.17 & 107.20 & 105.64 & 1.56 & $97 \%$ & 218.78 & 213.81 \\
SYPL & 486.92 & 239048.3 & 14960.17 & 254008.5 & 103.50 & 100.41 & 3.09 & $94 \%$ & 974.03 & 200.04 \\
SYH & 3982.29 & 15891677 & 983766 & 16875443 & 103.15 & 100.10 & 3.05 & $94 \%$ & 7939.23 & 199.36 \\
HSW & 30.48 & 2697.51 & 1269.22 & 2824.44 & 174.36 & 170.39 & 3.97 & $95 \%$ & 103.80 & 340.55 \\
BYPL & 1.93 & 0.81 & 0.15 & 0.95 & 50.50 & 46.34 & 4.16 & $84 \%$ & 1.68 & 86.82 \\
HI & 67.87 & 918.34 & 438.56 & 1356.9 & 54.27 & 53.65 & 0.62 & $67 \%$ & 50.74 & 74.75 \\
\hline
\end{tabular}

$\mathrm{DE}=$ Days to Emergence, $\mathrm{DFI}=$ Days to flowering initiation, $\mathrm{DF}=$ Days to $50 \%$ flowering, $\mathrm{PHF}=\mathrm{Plan}$ height at flowering in centimeter, $\mathrm{NPB}=$ number of primary branches per plant, $\mathrm{NSB}=$ number of secondary branches per plant. $\mathrm{PL}=$ Pod length in centimeter, $\mathrm{PT}=$ Pod thickness in centimeter, $\mathrm{NPP}=$ Number of pod per plant, $\mathrm{SNPP}=\mathrm{Seed}$ number per pod, $\mathrm{NSP}=$ number of seed per plant, $\mathrm{DM}=$ Days to maturity, $\mathrm{SYP}=$ Seed yield per plant in gram, SYPL $=$ Seed yield per plot $(\mathrm{g}), \mathrm{SYH}=$ Seed yield per Hectare $\left(\mathrm{Kgha}^{-1}\right), \mathrm{HSW}=$ hundred seed weight $(\mathrm{g}), \mathrm{BYPL}=$ Biomass Yield per plot $(\mathrm{Kg}), \mathrm{HI}=$ Harvest index in percentage, $\mathrm{W}=$ the difference between $\mathrm{PCV} \%$ \& $\mathrm{GCV} \%$.

\section{Estimation of heritability in broad sense}

Estimation of broad sense heritability for the studied traits was depicted in Table 6. The magnitude of the estimated broad sense heritability in this study ranged from $67 \%$ for the trait harvesting index to $98 \%$ for plant height at flowering. If heritability value of a trait for a given experiment is high, there is more considerable influence of genetic effect on the expressions of the trait than that of environmental effect. As a result, there is high possibility of improvement for those characters through selection. In this current study, high broad sense heritability was observed for all different tested traits indicating that the possibility of effective selection for these traits. However, selection of phonotypically superior accession will not lead to improvement due to the masking effect of the environment on the genotypic effect.

\section{Estimation of Expected Genetic Advance (GA) and Genetic Advance as percent of Mean (GAM)}

As it could be observed from Table 6, there was relatively high genetic advance for traits such as plot converted yield to hectare per plant (7939.23), number of secondary branches (261.21) followed by seed yield per plant (218.78), days to flowering initiation (123.18), hundred seed weight (103.80), number of pods per plant, NPP, (82.12), plant height at flowering (62.87) and harvest index (50.74). Therefore, these traits which showed high heritability values together with high genetic advance as percent of means indicated the possibility to improve white lupin through selection. Moderate genetic advance were noted for the trait days to $90 \%$ maturity (43.60), days to $50 \%$ flowering (43.45) followed by number of secondary branches (12.21). Nevertheless, for the rest studied traits such as days to emergence (5.27), number of primary branches (5.44), pod length (6.08) and others low estimated genetic advance was observed. Genetic gain that is expected from selecting the top 5\% of the genotypes, as a percent of mean varied from for the trait days to $90 \%$ maturity $(22.37 \%)$ to hundred seed weight $(340.55 \%)$, Table 6 .

\section{Discussion}

The present study evaluated each stated white lupin germplasm collections in terms of some of their morphological traits. As it could be understood from Table 1 showing geographic origin and administrative units (Zone, District and locality) of Ethiopian white lupin accessions, the plant is growing in northern part of Ethiopia only; particularly in Amhara National Regional state. White lupin has been under production in different administrative regions of Ethiopia [2, 9]. However, the CSA, 2014 [9] reports indicated that the Amhara National Regional state is the major 
producer and contributor to the national total production.

From the estimated mean square values due to environmental interaction, location, there is significant and highly significant difference among the tested accessions for $50 \%$ of the traits at $\mathrm{P} \leq 0.05, \mathrm{P} \leq 0.01$. For example, all the studied accessions showed highly significant differences in their four studied traits such as DE, PHF, PL and SYP due to the difference in location, Table 4. As reported by [25] significant differences between the Egyptian white lupin landraces in yield and yield related components in different environments but seasonal variance was insignificant for plant height, number of branches, pods per plant and seeds per pod. Significant intraspecific variations were reported among Ethiopian white lupin landrace accessions [1] and also among accessions from other parts of the world [26, 27] for grain yield, disease resistance and other important agronomic traits. Plant height at flowering ranges from the shortest accession (AC29054) which was $56 \mathrm{in} \mathrm{cm}$ to the longest one (AC29057) which is $137.83 \mathrm{~cm}$ long. Only three of the accessions AC29055 (82.5 cm), AC216016 (80.33 cm) and AC239017 $(85.5 \mathrm{~cm})$ exhibited nearly similar height to the grand mean value $(82.2 \mathrm{~cm})$. This result can be supported by the idea of very recently published research work Lupinus albus L. landraces can grow up to $146 \mathrm{~cm}$ tall [12]. In the study carried out by [28] the maximum seed yield per plant was reported as $38.3 \mathrm{~g}$ which is more approached to the minimum value of SYP obtained in this research.

According to [29] conducted research on genetic variability among yield, yield related traits in Ethiopian garden cress and then described both Phenotypic Coefficient of Variation (PCV) and Genotypic Coefficient of Variation (GCV) are components of variance estimation. The phenotypic coefficient of variation (PCV) which indicated the proportional influence of environmental variation to the total variation was greater than that of the genotypic coefficient of variation (GCV) for all the studied traits. However, the combined analysis over the two locations revealed that the GCV value, for all traits, is very approach to the estimated PCV value, Table 6. High GCV indicates that had high potential for effective selection [30]. Most of the traits showed small differences between the GCV and PCV which indicated that the observed variation for the trait was mostly due to genetic factors and hence heritable. Thoughthe study in [31] categorize range of PCV and GCV as low (0-10\%), medium (10-20\%) and high (above 20\%) in coriander. The differences between PCV and GCV were accounted to the environmental conditions under which the accessions were grown. The extents of the difference between PCV and $\mathrm{GCV}$ indicate degree of environmental influences on the traits. In this investigation the difference between PCV and GCV ranges from 0.39 in the trait pod length, PL, to 4.30 in days to maturity, DM, which indicate significant environmental influence on the expression of the trait DM; whereas it was negligible for the trait PL, Table 6. This finding is in agreement with the study reported by [1], the difference between PCV and GCV ranged from 0.61 in days to maturity to 8.42 in number of pods per plant which indicate significant environmental influence on the expression of number of pods per plant; whereas it was negligible for days to maturity.

Generally, in this study, for all traits the values of phenotypic variance $\left(\sigma^{2} \mathrm{P}\right)$ exceeded that of genotypic variance $\left(\sigma^{2} \mathrm{~g}\right)$, though the difference is small. This indicates that environmental variance $\left(\sigma^{2} \mathrm{e}\right)$ had its own contribution on the performance of the traits in addition to genotypic variance. The clear reason for this is that phenotypic variance is the sum total of genotypic variance and environmental variance. However, as it could be observed from the result, Table 6 , the values of phenotypic variance and genotypic variance were almost close to each other. This further indicates that the contribution of environmental variance $\left(\sigma^{2} \mathrm{e}\right)$ was less than that of genotypic variance. Therefore, it is possible to conclude that the variability in this study was due to genotypic variance. A wide range of variability among Moroccan Lupinus germplasm was observed [32]. Genetic coefficient of variation together with heritability estimates would give the best indication of the amount of gain due to selection $[1,33]$. Therefore, there could be better chance for improvement of the above traits with the relatively highest value genotypic coefficient of variation. It is not possible to determine the amount of the variation that was heritable only from the genotypic coefficient of variation. Genetic coefficient of variation together with heritability estimates would give the best picture of the amount of advance to be expected from selection. Thus, the heritable portion of the variation could be more useful with the help of heritability estimates. Awas et al., 2015 [34] categorize range of Heritability as low (0-20\%), medium (20-60\%) and high (above $60 \%)$. The existence of relatively high heritability in a given trait indicates that the presence of more additive gene effects for possible improvement. Since high heritability alone does not always guarantee high genetic gain from selection, heritability should be considered combined with genetic advance in predicting selection for superior genotypes. Genetic advance indicates the degree of gain in a character obtained under a particular selection pressure and helps the breeder to predict the extent of improvement that can be achieved in different characters. To predict the selection effect precisely, heritability accompanied with the genetic advance is more useful than heritability alone $[12,33]$. High broad sense heritability for seed weight in European white lupin genotypes was reported which agrees to the current findings [35]. High heritability indicates high proportion of genetic variance that could be inherited and would be exploited by breeders to select superior genotypes based on phenotypic performance [36,37]. This is because of high heritability can not always associated with high genetic advance [36]. Genetic coefficient of variation, GCV, together with heritability estimate would seem to give the best picture of the amount of genetic advance to be expected from selection $[33,34]$. High GCV along with high $\mathrm{h}^{2}$ and high GA would give better information than 
the individual parameters [38]. Similarly, high values of genetic parameters for the traits under study are the indication of additive gene action and hence the possibility of improvement of these traits through selection [39].

\section{Conclusion}

In conclusion, the present investigation indicated that there is wide range of genetic variability in the tested germplasm for most of the characters studied. Hybridization among accessions from different accessions identified in this study could lead to considerable genetic improvement by following appropriate selection strategies in the segregating generations. However, it would be worthwhile to study more available germplasm over years and locations to identify more diverse accessions as well as to confirm the importance of the traits identified as predictors of seed yield and/or oil content. At both locations, the phenotypic coefficient of variation (PCV) was higher than the genotypic coefficient of variation (GCV) which indicates the observed variation was not only due to genotypes but also environment. Hybridization among accessions from different clusters identified in this study could lead to considerable genetic improvement by following appropriate selection strategies in the segregating generations. In general, maximum genetic segregation and genetic recombination is expected from crosses that involve parents from highly significant distant clusters. In the present investigation, therefore, crossing of accessions from cluster three and five will give rise to maximum genetic segregation. The principal component analysis and cluster diagram based on Euclidian dissimilarity using group average method indicated that there was high variability among genotypes. Therefore, this variability would be high potential for genetic improvement of white lupin genotypes. The selection of parents which are identified on the basis of genetic variability would be more promising for a hybridization program.

\section{Conflicts of Interest}

The authors declare that there is no conflict of interest.

\section{Acknowledgments}

The author acknowledges the financial assistance provided by Ethiopian Ministry of Education and Madda Walabu University. I also gratefully acknowledge Mr. Tadesse Adere for his assistance in collecting data during field work, because of I conducted this research at the nearest sites of his experimental sites during his Master Thesis research at both locations

\section{REFERENCES}

[1] Atnaf M, Tesfaye K, Dagne K, Wegary D (2015b). Extent and pattern of genetic diversity in Ethiopian white lupin landraces for agronomical and phenological traits. Afr Crop Sci J. 23: 327 - 341.

[2] Tadesse Adere and Temesgen BedassaGudeta (2019). Genetic Divergence Analysis of Ethiopian White Lupine (Lupinus albus L.) Accessions in Bale Zone, South East, Ethiopia. Acad. Res. J. Agri. Sci. Res. 7(1): 21-30

[3] Wolko B, Clements JC, Naganowska B, Nelson MN, Yang H (2011). Lupinus. In: C Kole (ed.) Wild crop relatives: genomic and breeding resources. Springer. Berlin, Heidelberg. pp 153-206.

[4] Kurlovich BS (2002). The history of lupin domestication. Chapter 5. In: Kurlovich BS(Ed.) Lupins (geography, classification, genetic resources, and breeding). OY International North Express. St. Petersburg, Russia-Pellosniemi, Finland. pp. 147-164.

[5] Vipin, C.A., Luckett, J.D., Harper, I., Ash, G.J., Kilian, A., Ellwood, S.R., Phan, H.T.T. and Raman, H. (2013). Construction of linkage map of a recombinant inbred line population of white lupin (Lupinus albus L.). Breeding Science, 63: 292-300.

[6] Small, E. (2012). Lupinus-benefit and harm potentials. Biodiversity, 13: 54-64.

[7] Yeheyis, L., C. Kijora, E. van Santen, M. Wink,J.Danier and K.J. Peters (2012). Crude protein, amino acid and alkaloid contents of annual sweet lupin (Lupinus spp. L.) forages and seeds growing in Ethiopia. Exp. Agric., 48: 414-427.

[8] Zerihun N. (2012). Contribution of White lupin (Lupinus albus L.) for Food Security in Northwestern Ethiopia: A Review. Asian Journal of Plant Sciences 11 (5): 200-205.

[9] CSA, Central Statistical Agency, (2014). Ethiopian Agricultural sample survey 2013/2014 (2004 E.C.) area and production of major crops, Statistical Bulletin (I): 124 .

[10] Gonzalez-Andres F, Casquero PA, San-Pedro C, Hernandez-Sanchez E. (2007). Diversity in white lupin (Lupinus albus L.) landraces from Northwest Iberian plateau. Genet Resour Crop Ev. 54: 27-44.

[11] Arab S. A., Nahas M. El, R. M. Khalaf and Hussin M. E. (2014). Morphological and Cytological Characterization of Some White Lupin Landraces Collected from Egypt. Egypt. J. Agron. 36: 219 - 234

[12] Atnaf M., Tesfaye K., Yao N., Martina K. Dagne K. and Wegary D. (2017). Molecular genetic diversity and population structure of Ethiopian white lupin landraces Implications for breeding and conservation. https://doi.org/10.1371/journal.pone.0188696 
[13]EBC (2017). Ethiopian Biodiversity Conservation. Addis Ababa, Ethiopia

[14] Bekele F., Nega Mosisa, Dejen Terefe. (2017). Analysis of current rainfall variability and trends over BaleZone, South Eastern highland of Ethiopia. Climate Change, 3(12), 889-902.

[15]Jin Y. R.P. Singh, M. Pumphrey, Tadasse Kebede (2015). Phenotypic and Geneotypic characterization of Race TKTTF of $P$. graminis $\mathrm{f}$. sp tritici that caused a wheet stem rust Epidemic in Southern Ethiopia in 201314.

[16] Cochran, W.G. and G.M. Cox (1957). Experimental Designs. 2nd Edn., John Wiley and Sons, coefficient analysis on yield attributes in Root Knot Nematode Resistant F1 hybrids of tomato. J. Appl. Sci. Res. 4:287295 crested wheat grass seed production. Agron. J. 51:515-518

[17] Gomez AK, Gomez AA (1984). Statistical procedures for agricultural research. 2nd ed. Wilney Int. Sci., New York, P. 680.

[18]Burton.G.W and E.H Devance (1953). Estimation of heritability in tall festuca (Festucaarudindces) from replicated clonal material Agronomy J.45, 78-481.

[19] Singh B.D. (1993). Plant breeding principle and methods. Kalian publistrares Ludhiana new. Delti.

[20] Allard R,W. (1960). Principles of plant breeding, John wilky and sores inc, New York.

[21] Falconer D.S. (1993). Introducation to aquantative, genetics 3rd, John wiley and sons, inc, New.

[22] Robinson, H. F., Comstock, R. E. and Harvey, P. H. (1949). Estimates of heritability and degree of dominance in corn. Agronomy Journal, 41: 353-359.

[23] Miller, P.A., Wiliams, J.C. and Comstock, H.F. (1958). Estimation of genetic and environmental variance in upland cotton and their implications in selection. AgronomyJournal, 50:126-131.

[24] Robertson G.E. (1959). The sampling variance of genetic correlation coefficient Blo.15; 469-485.

[25] Raza, S. and B. Jornsgard (2002). Screening of white lupin accessions for morphological and yield traits. African Crop Science Journal $13: 135-141$

[26] Raman R, Cowley RB, Raman HD, Luckett J. (2014). Analyses using SSR and DArT molecular markers reveal that Ethiopian accessions of white lupin (Lupinus albus L.) represent a unique gene pool. Open J Genet. 4:87-98.

[27] Rubio J, Cubero JI, Martin LM, Suso MJ, Flores F. (2004). Biplot analysis of trait relations of white lupin in Spain. Euphytica. 135: 217-224.

[28]El-Harty E., Ashrie A., Ammar M.And Alghamd S. (2016). Genetic Variation Among Egyptian White Lupin (Lupinus Albus L.) Genotypes. Turk J Field Crops, 21: 148-155

[29] Temesgen Bedassa, Mebeaselassie A. and Million E. (2013b). Genetic divergence analysis of garden cress (Lepidium sativum L.). 5(11), pp. 770-774, November 2013. http://www.academicjournals.org/IJBC.

[30] Khayatnezhad, MR., Shahriari, BR., Gholamin RG. (2011). Correlation and Path Analysis between Yield and Yield Components in Potato (Solanum tubersum L.). J. Sci. Res. 7: 17-21.

[31] Dyulgerov, N. and Dyulgerova, B. (2014). Heritability and correlation coefficient Analysis for fruit yield and its components in coriander (Coriandrum sativum L.). Turkish Journal of Agricultural and Natural Sciences, 1: 618-622.

[32] Sbabou, L., Brhada, F. Alami, I.T. and Maltouf, A.F. 2010. Genetic diversity of Moroccan Lupinus germplasm investigated using ISSR and AFLP markers. International Journalof Agricultural Bioogy, 12: 26-32.

[33] Johnson, H.W., H.F. Robinson and R.E. Comstooc. (1955). Estimates of genetic and environmental variability in soybeans. Agronomy Journal. 47: 314-318.

[34] Geremew Awas, Firew Mekbib and Amsalu Ayana (2015). Variability, Heritability and Genetic Advance for Some Yield and Yield Related Traits and Oil Content in Ethiopian Coriander (Coriandrum sativum L.) Genotypes. International Journal of Plant Breeding and Genetics 9: 116-125, 2015.

[35] Annicchiarico P, Harzic N, Carroni AM. (2010). Adaptation, diversity, and exploitation of global white lupin (Lupinus albus L.) landrace genetic resources. Field Crops Res. 119:114-124.

[36] Tazeen M, Nadia K, Farzana NN. (2009). Heritability, phenotypic correlation and path coefficient studies for some agronomic characters in synthetic elite lines of wheat. J Food Agric Environ. 7: 278 - 282.

[37] Peter MV, William GH, Naomi RW. (2008). Heritability in the genomics era: concepts and misconceptions. Nat Rev Genet. 9:255-267.

[38] Tesfaye, W., Adugna, W. and Tewodros, M. (2014). Analysis of Genetic Parameters on Ethiopian Mustrad (Brassica carinata A. Braun) Genotypes in Northwestern Ethiopia. Agricultural Research Journal 4 (4): 8388.

[39] Dutta, P., Dutta, P.N. and Borua, P.K. (2013). Morphological Traits as Selection Indices in Rice: A Statistical View, Universal Journal of Agricultural Research, 1: 85-96. 